\title{
Endogenous Price Stickiness and Business Cycle Persistence
}

\author{
Michael T. Kiley \\ Division of Research and Statistics* \\ Board of Governors of the Federal Reserve System \\ Washington, DC 20551 \\ e-mail: mkiley@frb.gov
}

First Draft: March 24, 1995

This Draft: July 18, 1996

I would like to thank Michael Binder, David Bowman, Guillermo Calvo, Allan Drazen, John Driscoll, John Haltiwanger, Prakash Loungani, Ron Michener, Plutarchos Sakellaris, Michael Veall, and workshop participants at the Federal Reserve Banks of Kansas City and New York, the Federal Reserve Board, McMaster University, Rutgers University, the 1996 Summer Institute, the University of Michigan, the University of Virginia, and Washington University for their comments on an earlier draft of this paper. This research was supported by the Economic Club of Washington and an internship at the Division of International Finance of the Federal Reserve Board. The views and opinions expressed herein do not reflect those of the Board of Governors, the Federal Reserve System, or its staff. Responsibility for all remaining errors lies solely with the author.

*After July, 1996 


\title{
Endogenous Price Stickiness and Business Cycle Persistence
}

\begin{abstract}
This paper presents a model with imperfect information and price stickiness. In the model, both imperfect information and nominal price rigidity allow nominal shocks to act as business cycle impulses, but only sticky prices propagate the real effects of nominal shocks over time. The model indicates that high rates of inflation lead to less nominal price rigidity, and hence less persistent fluctuations of output about trend. Estimation of the model, as well as simple autocorrelations of detrended real output, indicate that indeed output fluctuations about trend are less persistent in high inflation economies. These results lend little support to equilibrium business cycle models in which the persistence of output fluctuations is explained through persistent real shocks, capital accumulation, or capital and labor adjustment costs
\end{abstract}

JEL Codes: E32, E31 
Accordingly we find, that, in every kingdom, into which money begins to flow in greater abundance than formerly, every thing takes a new face: labour and industry gain life... This is not easily to be accounted for, if we consider only the influence which a greater abundance of coin has in the kingdom itself, by heightening the price of commodities... To account, then, for this phenomenon, we must consider, that though the high price of commodities be a necessary consequence of the encrease of gold and silver, yet it follows not immediately upon that increase... At first, no alteration is perceived; by degrees the price rises, first of one commodity, then of another...

David Hume (1752) ${ }^{1}$

The two most prominent explanations over the past 25 years for the real output effects of nominal aggregate demand fluctuations are anticipated in the last line quoted from Hume: imperfect information about nominal fluctuations (as emphasized by Lucas $(1973,1987)$ ), and short-run nominal rigidities. The model presented below integrates both imperfect information and sticky prices in a single framework endogenously through costly information and costs of nominal price adjustment. The model emphasizes the importance of both imperfect information and sticky prices in determining the impact of nominal shocks on real variables, and the importance of sticky prices in propagating the real effects of nominal shocks through time.

Estimation of the model and simple examination of cross-country differences in output persistence both indicate that sticky prices are a more likely explanation for the persistence of the business cycle than neoclassical propagation mechanisms such as capital accumulation or persistent real shocks.

The incorporation of costly information naturally gives rise to imperfect information about monetary movements as posited in the signal extraction models of Lucas (1972,1973), but the real effects of these monetary shocks will be short-lived without a propagation mechanism

\footnotetext{
${ }^{1}$ As reproduced in Rotwein (1955) pp.37-38.
} 
significantly more effective than capital accumulation (see, for example, Cooley and Hansen (1995)). Sticky prices provide one such effective propagation mechanism, as has been well demonstrated in, for example, overlapping contracting models such as Taylor (1980). The model below should be viewed as a variant of models such as Taylor (1980) in which sticky prices are the primary propagation mechanism. Unlike Taylor (1980), the model below does not constrain firms to set prices without current information; the level of information firms possess when setting prices depends on whether the firm is willing to spend resources on information acquisition. The combination of information imperfections and nominal rigidity yields a model that nests imperfect information and sticky price models estimated in previous work (Lucas (1973), Ball, Mankiw, and Romer (1988), and Rotemberg (1994) are prominent examples).

The emphasis of the framework developed herein on price stickiness as a propagation mechanism has many precedents, but the central prediction of menu cost models that high inflation reduces price stickiness, and hence should reduce the persistence of output deviations from trend, has not been examined. Estimation of the model provides the first cross-country evidence suggesting that sticky prices are a major business cycle propagation mechanism; simply put, the evidence suggests that persistent deviations of output from trend begin to disappear as average inflation rises because the persistence generating mechanism (sticky prices) disappears. The systematic relationship between inflation and output persistence documented in section III is clearly consistent with a wide class of models in which nominal price rigidity is endogenous (as in the model of section I). It is difficult to reconcile the systematic relationship between inflation and output persistence with models in which prices are perfectly flexible and output persistence is driven by capital accumulation and the persistence of technology shocks, as inflation does not 
significantly affect the business cycle dynamics in those models (see Cooley and Hansen (1995) for an example and references).

The paper is organized into four sections. Section I presents a simple model with endogenous information and sticky prices. Section II discusses the role of price stickiness as a propagation mechanism. Section III presents the cross-country empirical results which emphasize how higher inflation reduces the persistence of real output fluctuations through decreases in price stickiness. Section IV concludes.

\section{The Model}

The model is a variant of Calvo (1983) in which individual firms face a constant probability (hazard) of adjusting their nominal price. This assumption captures the notion of fixed prices at the firm level while allowing for smooth adjustment of the aggregate price level (as a constant hazard model at the firm level leads to partial adjustment at the aggregate level (Rotemberg (1987), Caballero and Engel (1993)). The presentation of Calvo (1983) is altered by endogenizing the probability of price adjustments, thereby allowing for the (average) frequency of adjustment to vary with the parameters driving movements in the fundamentals affecting desired prices (as in Romer (1990)). The model is set in discrete time, which facilitates empirical implementation. The model also incorporates costly information acquisition. While the potential importance of information costs has been acknowledged in the menu cost literature (Ball and Mankiw (1994)), previous information cost models (Caballero (1989) and Andersen (1994)) do not contain any mechanism generating price rigidity, and therefore cannot generate sluggish adjustment to perceived shocks. While highly stylized, the model is a simple framework in which the basic intuition of the menu cost and imperfect information literatures can be captured. 
Section A introduces notation, and describes the menu cost and information cost specifications employed. Section B describes the choices of firms within the model.

\section{A. Notation}

Consider an economy consisting of a continuum of firms (distributed over [0.1]) whose $(\log )$ desired nominal prices $\left(\mathrm{x}_{\mathrm{it}}\right)$ depend on the $(\log )$ money supply $\left(\mathrm{m}_{\mathrm{t}}\right)$ (i.e. aggregate demand) and idiosyncratic demand/supply factors $\left(\mathrm{u}_{\mathrm{it}}\right)$ (i.e. relative price shocks):

$$
\mathrm{x}_{\mathrm{it}}=\mathrm{m}_{\mathrm{t}}+\mathrm{u}_{\mathrm{it}}
$$

The loss from deviations of nominal prices $\left(\mathrm{p}_{\mathrm{it}}\right)$ from desired prices is quadratic,

$$
(1 / 2) \mathrm{K}\left(\mathrm{p}_{\mathrm{it}}-\mathrm{x}_{\mathrm{it}}\right)^{2} \text {. }
$$

This specification is standard throughout the menu cost literature, and can be derived in a utility maximizing model in which firm/consumers produce differentiated products and the quadratic loss function is a second order approximation to the firm/consumers' indirect utility function. ${ }^{2}$

To illustrate the intuition behind nominal price rigidity and information acquisition, the money supply and relative price shocks are random walks:

$$
\begin{aligned}
& \mathrm{m}_{\mathrm{t}}=\mu+\mathrm{m}_{\mathrm{t}-1}+\epsilon_{\mathrm{mt}} \\
& \mathrm{u}_{\mathrm{it}}=\mathrm{u}_{\mathrm{it}-1}+\epsilon_{\mathrm{uit}}
\end{aligned}
$$

where $\mu$ is the mean rate of money growth, and $\epsilon_{\mathrm{mt}}$ and $\epsilon_{\text {uit }}$ are i.i.d. Normal with mean zero.

\section{A.i. Price Adjustment}

Due to a fixed cost of price adjustment $\mathrm{F}$, firms find continual adjustment of nominal prices to be suboptimal. In a model with perfect information, the optimal price adjustment policy for individual firms would be some variant of a state-dependent price adjustment policy, in which

\footnotetext{
${ }^{2}$ References to the menu cost literature are contained in Ball and Mankiw (1994).
} 
the probability of price adjustment in any period depends on the size of the deviation from the desired price. ${ }^{3}$

Several problems arise in applying the state-dependent approach in this paper. First, optimal price adjustment policies have been derived only under restrictive assumptions, so that deriving closed form solutions for empirical implementation when money follows a more general process than (3) (as in sections II and III below) is still an open area of research. Moreover, the aggregate implications of these adjustment policies depend on the distribution across price setters of deviations from desired prices. Measuring such a cross-sectional distribution requires highly disaggregated data and hence precludes a large cross-country study (because of missing data). Finally, the optimal adjustment policies studied thus far assume perfect information; the form of optimal adjustment policies in an imperfect information environment like that of this paper requires further research.

To circumvent these problems with a time varying probability of price adjustment, I assume firms choose a constant probability of changing price in any period ( $\pi$ ) (Calvo (1983), Romer (1990)). The choice of $\pi$ occurs in a period when the firm has the opportunity to change its nominal price, and remains constant until the next opportunity the firm has to change its nominal price (on average $1 / \pi$ periods after the last price change), at which time a new $\pi$ can be chosen. The assumption that price changes at the firm level occur in any period with some constant probability captures the notion of fixed prices at the firm level, while allowing for smooth aggregate price level movements (as some firms will adjust in each period). Of course, a constant

\footnotetext{
${ }^{3}$ Caballero and Engel $(1992,1993)$ are examples of menu cost models enriched by consideration of state-dependent price adjustment.
} 
$\pi$ loses some degree of realism; presumably price adjustment is more probable the larger the deviation from desired price, as in state-dependent models. The assumption of a constant $\pi$ does allow the model to capture some of the most important features of more general formulations. For example, the average time between price adjustment $(1 / \pi)$ will be lower in economies with higher average inflation/money growth $(\mu)$. The hope is that this simplification captures the basic notion of cross-country differences in price rigidity. I will show that the solution of the model encompasses a number of previous models as special cases.

\section{A.ii. Information Acquisition}

Information gathering about optimal prices (the state of the money supply and relative price factors) is costly. The "information cost" (cost of determining the optimal relative price) is captured by the assumption that a firm chooses whether to maintain a marketing or "information" division which determines the current desired price $\left(\mathrm{x}_{\mathrm{it}}\right)$ when the firm changes price. To maintain the marketing or information division, the firm must incur a fixed $\operatorname{cost}(\alpha)$ in each period (in order to hire market analysts). The fixed $\alpha$ differs across firms; specifically, I assume that the fixed cost of an information division to a firm is a constant $\alpha \in(0, \infty)$ drawn from the distribution $\mathrm{G}($.$) . When$ a firm without an information division changes price, the firm adjusts based on one period lagged information. A firm may choose whether to maintain an information division in those periods when it changes its nominal price, and the decision is then fixed until the firm again changes its nominal price. Under these assumptions, some fraction $\Theta$ of firms purchase information and some fraction $(1-\Theta)$ of firms do not purchase information.

As in the discussion of the simplifying assumption regarding a constant probability of price adjustment, the formulation of firms' information decisions is meant to capture in as simple a 
framework as possible the notion that firms do not always find the gain from information acquisition worth the expense by modeling the determinants of the average level of information $(\Theta)$. By focusing only on the average level of information purchased by firms, aggregate implications for output fluctuation differences across countries are derived below which encompass popular alternative models (in particular, this characterization of the information problem facing firms leads to a reduced form identical to that of Lucas (1973)).

\section{B. Price and Information Decisions}

Under the above assumptions about the nature and timing of firms' price adjustment policies and the structure of information costs, firms choose their average frequency of price adjustment $(1 / \pi)$, whether to maintain information divisions, and the nominal price of their

product in order to minimize the present discounted value of the losses incurred because of menu costs, information costs, and the deviation of nominal from desired prices. Denote by $\mathrm{I}_{\mathrm{t}}^{\mathrm{fi}}$ the information set of a firm with full information at time $t$ (consisting of the entire history of shocks up to period $t$ because the firm maintains an information division), and by $\mathrm{I}_{\mathrm{t}}^{\mathrm{pi}}$ the information set of a firm with imperfect information (consisting of the entire history of shocks through period t1). The present discounted value of losses assuming adjustment at $t$ with full information $\left(\mathrm{V}_{0}{ }_{0}^{\mathrm{fi}}\right.$, where the subscript 0 indicates the number of periods since last price adjustment) and the present discounted value of losses assuming adjustment at $\mathrm{t}$ with partial information $\left(\mathrm{V}_{0}^{\mathrm{pi}}\right)$ are then

$$
V_{0}^{f i}=E_{I_{t}^{f i}} \sum_{s=t}^{\infty}\left[\alpha+\frac{K}{2}\left(p_{i t}^{f i}-x_{i s}\right)^{2}\right]((1-\pi) \rho)^{s-t}+\pi\left(F+V_{0}^{f i}\right) \sum_{s=t+1}^{\infty} \rho^{s-t}(1-\pi)^{s-t-1}
$$




$$
V_{0}^{p i}=E_{I_{t}^{p i}} \sum_{s=t}^{\infty}\left[\frac{K}{2}\left(p_{i t}^{p i}-x_{i s}\right)^{2}\right]((1-\pi) \rho)^{s-t}+\pi\left(F+V_{0}^{p i}\right) \sum_{s=t+1}^{\infty} \rho^{s-t}(1-\pi)^{s-t-1}
$$

where $\rho$ is the discount factor. The first term in the expression for the full information firms includes the cost of maintaining the information division $(\alpha)$, and the losses from deviations of nominal price $\mathrm{p}_{\mathrm{t}}$ from desired price $\mathrm{x}_{\mathrm{t}}$. The low information firms do not need to pay to maintain an information division in each period, so the first term in (6) only includes the losses from deviations of nominal price from desired price. These losses (at $s>t$ ) are discounted by the time discount rate $\left(\rho^{s-t}\right)$, and the probability that nominal price adjustment has not occurred $\left((1-\pi)^{s-t}\right)$. The second term in each equation represents the value of adjusting price at time s and starting the cycle anew, discounted by the time discount rate and the probability of occurrence. Note that under (3) and (4), a firm's minimization problem is recursive, i.e. the same nominal price, frequency of adjustment, and information decision will be chosen by a firm in future periods of adjustment as in period $\mathrm{t}$ (so $\mathrm{V}_{0}$ is the appropriate future value on the right hand side of (5) and (6)).

Solving (5) and (6) for $\mathrm{V}_{0}{ }^{\mathrm{fi}}$ and $\mathrm{V}_{0}{ }^{\mathrm{pi}}$, the expressions for the losses $\mathrm{V}_{0}$ under both information sets are

$$
\begin{gathered}
(1-\rho) V_{0}^{f i}=\frac{K}{2}[1-(1-\pi) \rho] E_{I_{t}^{f i}} \sum_{s=t}^{\infty}\left(p_{i t}^{f i}-x_{i s}\right)^{2}((1-\pi) \rho)^{s-t}+\pi \rho F+\alpha, \\
(1-\rho) V_{0}^{p i}=\frac{K}{2}[1-(1-\pi) \rho] E_{I_{t}^{f i}} \sum_{s=t}^{\infty}\left(p_{i t}^{p i}-x_{i s}\right)^{2}((1-\pi) \rho)^{s-t}+\pi \rho F .
\end{gathered}
$$

The menu cost $\mathrm{F}$ is incurred whenever price adjustment occurs (on average every $1 / \pi$ periods) by 
both high and low information firms, while the information division $\operatorname{cost}(\alpha)$ is continuously incurred by the information firm. These losses are then minimized with respect to $\pi, \mathrm{p}_{\mathrm{it}}{ }_{\mathrm{fi}}$, and $\mathrm{p}_{\mathrm{it}}{ }^{\mathrm{pi}}$. As the nominal price choices will not affect menu costs (cost associated with the frequency of price adjustment $1 / \pi$ ) or information costs, the expressions for $\mathrm{p}_{\mathrm{it}}{ }^{\mathrm{fi}}$ and $\mathrm{p}_{\mathrm{it}}{ }^{\mathrm{pi}}$ which result from taking derivatives of (7) with respect to nominal prices are simply:

$$
\begin{gathered}
p_{i t}^{f i}=[1-(1-\pi) \rho] E_{I_{t}^{f i}} \sum_{s=t}^{\infty} x_{i s}((1-\pi) \rho)^{s-t} \\
p_{i t}^{p i}=[1-(1-\pi) \rho] E_{I_{t}^{p i}} \sum_{s=t}^{\infty} x_{i s}((1-\pi) \rho)^{s-t},
\end{gathered}
$$

i.e. nominal prices under the different information sets are set to equal the weighted average of the desired price over the potential horizon when the nominal price is fixed, with the weight at s equal to the probability the price has not been changed by s times the discount factor for $\mathrm{s}$.

Given the assumed processes governing the components of $x_{i t}(3)$ and (4), the expectation of $x_{i s}$ given full information at time $t$ is $m_{t}+u_{i t}+\mu(s-t)$. The expectation of $x_{\text {is }}$ given partial information at time $t$ (consisting of the history of shocks dated $t-1$ and earlier) is $\left(m_{t-1}+\mu\right)+\mu(s-t)$ $+u_{\mathrm{it}-1}$.

Evaluating the expectations in the loss function leads to the following expression for the losses in (7) (given the expressions for $\mathrm{p}_{\mathrm{it}}{ }^{\mathrm{fi}}(8)$ and $\mathrm{p}_{\mathrm{it}}{ }^{\mathrm{pi}}(9)$ ): 


$$
\begin{gathered}
(1-\rho) V_{0}^{f i}=\pi \rho F+\frac{K \mu^{2}(1-\pi) \rho}{2[1-(1-\pi) \rho]^{2}}+\frac{K\left(\sigma_{m}^{2}+\sigma_{u}^{2}\right)(1-\pi) \rho}{2[1-(1-\pi) \rho]}+\alpha, \\
(1-\rho) V_{0}^{f i}=\pi \rho F+\frac{K \mu^{2}(1-\pi) \rho}{2[1-(1-\pi) \rho]^{2}}+\frac{K\left(\sigma_{m}^{2}+\sigma_{u}^{2}\right)(1-\pi) \rho}{2[1-(1-\pi) \rho]} \\
+\frac{K}{2}\left[\sigma_{u}^{2}+\sigma_{m}^{2}\right] .
\end{gathered}
$$

The second and third terms in (10a) are the losses from deviations of desired prices from nominal prices incurred by full information firms because of price rigidity. The fourth term in (10b) is the additional loss from deviations of desired prices from nominal prices incurred by low information firms because of imperfect information. The losses to high and low information firms are increasing in the growth rate of money, and the variance of desired price shocks $\left(\sigma_{\mathrm{m}}{ }^{2}+\sigma_{\mathrm{u}}{ }^{2}\right)$.

Inspection of $(10 \mathrm{a}, \mathrm{b})$ reveals that firms purchase information if $\alpha<\mathrm{K} \sigma_{\mathrm{z}}^{2} / 2$, where $\sigma_{\mathrm{z}}{ }^{2}=\sigma_{\mathrm{m}}{ }^{2}+\sigma_{\mathrm{u}}{ }^{2}$; therefore, the fraction of firms which purchase information $(\Theta)$ is given by

$$
\Theta=G\left(K \sigma_{z}^{2} / 2\right) .
$$

The first order condition for $\pi$ for both types of information firms is identical (as inspection of (10) reveals), indicating that both types of firms will choose the same frequency of price adjustment. Note that the equilibrium values of $\pi$ and $\Theta$ depend on total variability $\sigma_{z}^{2}$. The first order condition for $\pi$ and (11) imply the following proposition:

Proposition I: A. The average length between nominal price adjustments $(1 / \pi)$ is I) decreasing in the growth rate of money $(\mu)$, and ii) decreasing in the level of variability in desired prices $\left(\sigma_{z}^{2}\right)$.

B. The amount of information purchased $(\Theta)$ is I) increasing in the level of variability in desired prices $\left(\sigma_{z}^{2}\right)$.

The intuition is straightforward. Result A.i. simply says that as desired prices move more 
quickly, adjustment occurs more frequently. Result B.i. states that information is more desirable the more prices fluctuate. Similar intuition applies to A.ii. ${ }^{4}$

\section{Empirical Implications of Imperfect Information and Price Stickiness}

The model presented in the previous section can readily be adapted to provide an empirical framework identifying the degree of price stickiness, and the presence of imperfect information, through the relationship between real output and nominal output.

First note that eq. (1) expresses a firm's desired price as a function of nominal aggregate demand $\left(\mathrm{m}_{\mathrm{t}}\right)$ and idiosyncratic factors. Following Lucas (1973), Ball, Mankiw, and Romer (1988, henceforth BMR), and others, nominal aggregate demand in the model corresponds to nominal output for estimation.

The aggregate price level $\mathrm{P}_{\mathrm{t}}$ is (as discussed for the Calvo model (1983) with exogenous frequency of price adjustment by Rotemberg (1987))

$$
P_{t}=(1-\pi) P_{t-1}+\pi[1-(1-\pi) \rho] \sum_{j \geq 0}((1-\pi) \rho)^{j} E_{t} m_{t+j}
$$

The expectations term is an "aggregate expectation" weighting the expectations of contemporaneous information firms and lagged information firms by their shares in the economy. For example, when nominal aggregate demand or money follows a random walk as in $(3), \operatorname{Em}_{\mathrm{t}}=$ $\Theta m_{t}+(1-\Theta)\left(m_{t-1}+\mu\right)$. Thus the reduced form of expectations of nominal aggregate demand is identical to that of Lucas (1973), where in Lucas (1973) $\Theta$ corresponds to imperfect information due to signal extraction by firms.

\footnotetext{
${ }^{4}$ Results A.i. and B.i. are standard in the menu cost (Ball, Mankiw, and Romer (1988) and Caballero and Engel (1992)), and information cost literatures (Caballero (1989)). A.ii. need not be true when firm's price adjustment decisions can be state-dependent (Caballero and Engel (1992)).
} 
To examine seriously the empirical implications of the model, a more general time series process governing nominal aggregate demand than (3) is used:

$$
\Delta \mathrm{m}_{\mathrm{t}+1}=\mu+\mathrm{a} \Delta \mathrm{m}_{\mathrm{t}}+\epsilon_{\mathrm{t}+1} .
$$

This time series process ( $\operatorname{AR}(2)$ with a unit root) is often successful at explaining the behavior of macroeconomic aggregates. Using (12), (13), and the accounting identity relating the (logs of) real output $\left(\mathrm{y}_{t}\right)$, the price level $\left(\mathrm{p}_{t}\right)$, and nominal output $\left(\mathrm{m}_{\mathrm{t}}\right)\left(\mathrm{m}_{\mathrm{t}}=\mathrm{y}_{\mathrm{t}}+\mathrm{p}_{\mathrm{t}}\right)$ yields the following equations for real output and inflation (ignoring constants):

$$
\begin{aligned}
& y_{t}=\left(\frac{(1-\pi)(1-\rho a)}{1-a(1-\pi) \rho}\right)\left(\frac{1+\frac{(1-\Theta) \pi}{(1-\pi)(1-\rho a)}(1-a L)}{1-((1-\pi)+a) L+(1-\pi) a L^{2}}\right) \epsilon_{t}, \\
& \Delta p_{t}=\left(\frac{\pi}{1-a(1-\pi) \rho}\right)\left(\frac{\Theta+[(1+a)(1-\Theta)-a(1-\pi) \rho] L-(1-\Theta) a L^{2}}{1-((1-\pi)+a) L+(1-\pi) a L^{2}}\right) \epsilon_{t},
\end{aligned}
$$

where $\mathrm{L}$ is the lag operator. Eqs. (14) and (15) describe the time series behavior of inflation $(\operatorname{ARMA}(2,2))$ and output $(\operatorname{ARMA}(2,1))$.

The equation for output (14) encompasses several previous models as special cases. In the absence of price stickiness $(\pi=1)$ and assuming a random walk for nominal aggregate demand (a=0), (14) corresponds to the Lucas Phillips curve (1973) (as these were Lucas' assumptions), which imparts no serial correlation to real output. When information is perfect $(\Theta=1),(14)$ corresponds to Rotemberg's model of quadratic costs of price adjustment (1994).

Both Lucas and BMR (and others) assume that nominal aggregate demand is a random walk $(a=0)$. Notice that in this case, the persistence of real output movements when running a 
regression of (14) is entirely determined by the degree of price stickiness, i.e. 1- $\pi$ is the coefficient on lagged output. This result emphasizes that price stickiness is an outstanding propagation mechanism. While this result is exploited in certain macroeconometric models (Taylor (1993)), the implication that the persistence of deviations of output from trend should be inversely related to average inflation (which arises when price stickiness $(1-\pi)$ is endogenous from Proposition I) has not been empirically investigated. The next section explores this implication of the model, and contrasts the results with those of previous authors.

\section{Price Stickiness and Output Persistence: Empirical Results}

The interesting prediction stemming from (14) is that output fluctuations should be less persistent in countries with flexible prices. The following subsections explore this implication under different assumptions regarding the behavior of nominal output. The first subsection focuses on the relationship between the autocorrelation of real output and the average inflation rate in a country; if price stickiness is lower in high inflation economies, as suggested by the menu cost model of section I, then output fluctuations about trend should be less persistent. As the results of this exercise are encouraging, the following subsections examine the results of estimates of the model for several samples of countries under different assumptions about the behavior of nominal output.

\section{A. Average Inflation and the Autocorrelation in Real Output.}

The primary sample of countries considered is the 43 country sample over the period 1948-1986 used by BMR, as their study is a well known example of the work examining the implications of menu cost models for the impact of nominal shocks on output, and I wish to contribute to our understanding of nominal rigidity by exploring the implications of menu costs 
for real output persistence. ${ }^{5}$ Other samples are considered below. Table 1 reports the first two autocorrelations for HP and linearly detrended real output, and the average inflation rate for each country in BMR's sample. Table 2 reports the correlations between the autocorrelation in real output and the average inflation rate in the economy for various subsamples of BMR's sample. In the full 43 country sample, the correlations between the degree of persistence in real output and average inflation in the economy is negative and significant at the 5\% or $1 \%$ level for both HPfiltered and linearly detrended data. I also split the data into non-OECD and OECD samples; this split is designed to address the concern that less developed economies have less persistent business cycles (i.e. commodity cycles vs. investment cycles), and higher inflation on average. The results indicate that even within the non-OECD sample there is significantly less business cycle persistence in high inflation economies. The results for the OECD only sample are mixed; the linearly detrended output autocorrelations are significantly smaller in high inflation economies, but the HP-filtered output autocorrelations are not significantly smaller in the high inflation economies. This sensitivity is unsurprising given the small degree of variation in inflation experience across the OECD. In sum, these correlations strongly suggest less persistence in the fluctuations of real output about trend in high inflation economies, as predicted when sticky prices are endogenous (proposition I), and an important persistence generating mechanism (as in (14)). With these encouraging results in hand, the next section turns more closely to the model.

\section{B. Case 1: $a=0$.}

In this section, the relationship of the degree of price flexibility $(\pi)$ to the inflation rate is examined in the BMR sample under the assumption $\mathrm{a}=0$ in (13), as this is the standard assumption

\footnotetext{
${ }^{5}$ Thanks to Greg Mankiw for providing BMR's data.
} 
in this literature starting with Lucas (1973). Imposing $a=0$ in (13) and (14) yields the following equation for output:

$$
\mathrm{y}_{\mathrm{t}}=(1-\pi) \mathrm{y}_{\mathrm{t}-1}+(1-\pi \Theta) \Delta \mathrm{m}_{\mathrm{t}}
$$

where $\epsilon_{\mathrm{t}}=\Delta \mathrm{m}_{\mathrm{t}}$ (as a=0 in (13)) has been used. Note that price stickiness is reflected in the coefficient on lagged output, so a researcher interested in price stickiness should examine the coefficient on lagged output, not the coefficient on the change in nominal output as in BMR, Defina (1991), Caballero and Engel (1992), Walsh (1994), and others, unless $a=0$ and $\Theta=1$ in all countries. If price stickiness is lower in high inflation economies, the impact coefficient on $\Delta \mathrm{m}$ should be smaller as emphasized by the authors noted above, although the relationship is clouded in the presence of information imperfections $\Theta$. Proposition I.A. and (14b) also imply that high inflation economies should have less persistence in output fluctuations, and this relationship is not clouded by imperfect information $\Theta$.

I estimate (14b) for each country in BMR's sample using real output detrended by the Hodrick-Prescott filter. The results for $\pi$ are reported in table 3. As discussed in proposition I.A., price flexibility should increase with average inflation. Regressions of $\pi$ against the average inflation rate $(\Delta \mathrm{P})$ of each country in the BMR sample ${ }^{6}$ (heteroskedasticity consistent t-statistics in parentheses) yields

BMR: $\quad \pi=0.384+0.872 \Delta \mathrm{P}$
(11.14) (3.19)
Adj. $R^{2}=0.23$
$\mathrm{N}=43$.

${ }^{6}$ Proposition I suggests that both average inflation and the variability of nominal aggregate demand determine $\pi$. Unfortunately, the correlation across countries between average inflation and the standard deviation of nominal output growth is very high (0.92 in the BMR sample), so average inflation and variability carry basically the same information. I therefore focus solely on average inflation as a determinant of $\pi$; consideration of variability does not change the results in any important way, and reveals that average inflation is more strongly related to $\pi$ than is variability. 
The results show that countries with higher average inflation rates have more flexible prices (and hence through (14) less persistent deviations of real output from trend). Visual inspection of a plot of the $\pi$ 's against average inflation for the BMR sample (figure 1) confirms the regression results. The greater price flexibility in high inflation economies leads to less output persistence.

While the systematic relationship between output persistence and inflation supports a central prediction of endogenous sticky price models, a possible "spurious regression problem" clouds interpretation of estimates from (14b). Suppose that price stickiness and imperfect information were unimportant for aggregate output fluctuations, so that real output fluctuations solely reflected real shocks. Further suppose that real output growth $\left(\Delta \mathrm{y}_{\mathrm{t}}\right)$ and inflation $\left(\Delta \mathrm{P}_{\mathrm{t}}\right)$ were independent random variables. In such an environment, the regression (14b) would not yield a zero coefficient on $\Delta \mathrm{m}_{\mathrm{t}}$, even though nominal shocks have no real effects. This is because $\Delta \mathrm{m}_{\mathrm{t}}$ equals $\Delta \mathrm{y}_{\mathrm{t}}+\Delta \mathrm{P}_{\mathrm{t}}$ and hence (14b) is simply a regression of real output on a noisy measure of itself. Estimation of (14b) thus is a potentially poor strategy for looking at the importance of imperfect information and price stickiness. ${ }^{7}$ Moreover, $a=0$ may not be a good assumption. The next section pursues a different strategy.

\section{Case 2: $a \neq 0, \Theta=1$.}

The previous section provides new support for endogenous price stickiness models in which prices become more flexible at higher inflation rates, and this flexibility lowers the persistence of real output fluctuations. This section will relax the assumption imposed in many other studies that $\mathrm{a}=0$. The strategy of this section will seek to avoid the spurious regression

7 This point is noted in the comments on BMR by Akerlof, Rose, and Yellen, and Sims. Kiley (1995) applies this point to the relationship between central bank independence and the costs of disinflation. 
problem of the previous section. Controlling for $\mathrm{a} \neq 0$ is also important because differences across countries in the persistence of the driving force behind real output fluctuations (nominal output) will affect the persistence of real output (as seen in (14)). For example, high inflation economies may pursue policies which result in very little persistence in nominal output fluctuations, whereas low inflation economies may display greater persistence in nominal output fluctuations; this pattern would yield less persistent real output fluctuations in high inflation economies even if price rigidity were the same in high and low inflation economies. By controlling for the differences across countries in the persistence of nominal output fluctuations, greater confidence can be placed in associating less real output persistence with more flexible prices.

When $\mathrm{a} \neq 0,(14)$ implies that real output is an $\operatorname{ARMA}(2,1)$ process

$$
y_{t}=((1-\pi)+a) y_{t-1}-(1-\pi) a y_{t-2}+v_{t},
$$

where $v_{t}$ is the MA(1) function of $\epsilon_{t}$ in (14). The moving average disturbance becomes white noise in the absence of imperfect information $(\Theta=1)$. Note that $(14 \mathrm{c})$ avoids the spurious regression problem of the previous section by estimating an equation for real output which does not include the change in nominal output.

The strategy followed in this section is therefore: 1 . jointly estimate, for the detrended BMR data, (14c) and (13), while imposing the restriction $\Theta=1$ and the cross equation restrictions on $\mathrm{y}$ and $\mathrm{m}$, but without imposing the cross equation restrictions on $\mathrm{v}_{\mathrm{t}}$ and $\epsilon_{\mathrm{t}}$ (imposing these cross equations restrictions results in a singular covariance matrix for the system (14c) and (13) due to the simplicity of the model); 2. explore the relationship between this estimate of $\pi$ and inflation as in the previous section; and 3. test for the presence of a moving average error in (14c) in order to examine the empirical importance of imperfect information. Note that by not imposing 
the stochastic singularity of the model (i.e. the cross-equation restrictions on the error terms), I assume that the propagation of shocks to real output follows the predictions of my model, but the impulses to real output can come from other sources. This assumption is questionable, and hence the results should be interpreted with caution. My focus is on the implications of price stickiness for cross-country differences in business cycle persistence, so I believe my focus on the implications of price stickiness for the autoregressive roots of real output in (14c) is reasonable. The robustness of my conclusions to this identifying assumption are discussed below.

Following steps 1 and 2 for the 43 countries in the BMR data set using Hodrick-Prescott detrended output reveals that the assumption $\mathrm{a}=0$ used in many previous studies is overwhelmingly rejected by the data. As shown in Table 4, in only six countries is the null hypothesis of $\mathrm{a}=0$ not rejected at the $5 \%$ level (Austria, Dominican Republic, Finland, Nicaragua, Tunisia, and Venezuela) (only 3 countries do not reject the restriction at the $10 \%$ level - Finland, Nicaragua, and Tunisia). Table 4 also reports the new estimates of $\pi$ for the BMR sample.

Figure 2 plots the estimates of $\pi$ resulting from (14c) against inflation. Again, it appears that higher average inflation leads to greater price flexibility and hence less persistence in output fluctuations. Regressing $\pi$ against average inflation yields (heteroskedasticity consistent tstatistics in parentheses)

$$
\pi=\begin{aligned}
& 0.532+1.456 \Delta \mathrm{P} \\
& (14.10)(5.84)
\end{aligned} \quad \text { Adj. } \mathrm{R}^{2}=0.30 \quad \mathrm{~N}=43 .
$$

This estimate of $\pi$ is strongly related to mean inflation. This result supports the earlier conclusion arrived at in the $\mathrm{AR}(1)$ specification (i.e. $\mathrm{a}=0$ ) that price rigidity is an important propagation mechanism which explains a significant fraction of the cross-country differences in output 
persistence. $^{8}$

\section{Robustness I}

The previous three sections reveal that high inflation economies in the BMR sample experience less persistent fluctuations in real output. While the cross-country differences in real output persistence seem well characterized by differences in price stickiness (which will clearly be related to average inflation as shown in section I), several robustness checks seem in order. The first issue regards the method used to detrend real output. The previous results in the BMR sample detrend real output with the HP filter; all results are unchanged if output is detrended with a linear time trend.. The second issue regards using (14c) and (13) to estimate the structural parameter determining price stickiness, $\pi$. According to the model, $1 / \pi$ yields the average frequency of price adjustment. Taken literally, the results in table 4 would thus suggest that price adjustment is very infrequent (for example, greater than 3 years on average between price adjustments for the U.S.). This literal interpretation of $\pi$ thus seems implausible. However, it is well known that in staggered price adjustment models (Taylor (1980)), the real effects of nominal shocks persist long after all firms have adjusted due to the incorporation of relative price

8 With regard to imperfect information, remember $\Theta<1$ implies a MA(1) error in the AR(2) estimated for output. Ljung-Box Q-statistics (not reported) find no evidence of first order serial correlation in the errors of (14c) equations except for Bolivia, Greece, and Panama, where the hypothesis of no first order serial correlation is rejected at the 5\% level. These results provide little support for imperfect information, despite its theoretical importance. The values of $\theta$ recovered from (14b) in the BMR sample considered above also give little support to the imperfect information aspect of the model; $\theta$ tends to be greater than 1 and imprecisely estimated. The Lucas (1973) and Alberro (1981) samples considered below perform slightly better along this dimension (for example, in the Lucas sample $\theta<1$ in every country).

The negative results regarding imperfect information are not particularly surprising. First, the test for serial correlation is fairly weak given the small sample (Cuthbertson, Hall, and Taylor (1992)). More importantly, the crosscountry comparison above uses annual data (in order to ensure a large sample of countries with different inflation experiences), and an $\operatorname{AR}(2)$ does a good job of accounting for the serial correlation of annual output. Imperfect information is likely to be more important in a examination of quarterly data (a one or two quarter information lag is certainly more reasonable than an information lag of a whole year). As the focus of this paper is endogenous price stickiness and business cycle persistence (i.e., $\pi$ ), careful examination of $\theta$ is left to future work. 
considerations (which are absent from this model) in firms' price decisions. A loose interpretation of $1 / \pi$ as the result of the interaction of the frequency of price adjustment and the slow adjustment arising from relative price concerns seems consistent with the broad implications of sticky price theories. Moreover, as discussed in subsection A above and tables 1 and 2, the main point regarding the importance of price stickiness as a business cycle propagation mechanism which explains cross-country differences in real output persistence can be seen by looking at crosscountry differences in real output autocorrelations, rather than $\pi$. In this sense, the finding of less business cycle persistence in high inflation economies is independent of the identifying assumptions used in estimating the model.

Another test is to examine how robust these results are to a more recent sample of countries. The sample considered in this section was selected by: 1. Starting with BMR's original sample of 43 countries; 2. Expanding the time period to 1949-1994; 3. Deleting all Latin American and African economies because of the debt crisis (which resulted in inflation crises, and makes separation of trend and cycle problematic given the output stagnation experienced by many crisis countries); and 4. splitting the remaining sample into pre-1973 and post-1973 samples in order to increase the effective sample size of economies, and to examine the sensitivity of the results to time period. The data consists of real and nominal GDP (GNP when GDP is not availiable), and is taken from the May 1995 IFS CD-ROM. Estimates of $\pi$ from (14c), the first two autocorrelations of HP filtered real output, and the average inflation rate over the time period for the resulting 38 economies are reported in Table 5.

Regressing the estimates of $\pi$ from table 5 against average inflation for the pre- 73 and post-73 samples yields (heteroskedasticity consistent t-statistics in parentheses) 
pre-73: $\quad \pi=0.569+1.188 \Delta \mathrm{P}$

post-73: $\quad \pi=\quad \begin{aligned} & (4.02)(0.51) \\ & 0.452+0.886 \Delta \mathrm{P}\end{aligned}$

Adj. $R^{2}=-0.06 \quad \mathrm{~N}=16$

(11.58) (2.93) Adj. $\mathrm{R}^{2}=0.21 \quad \mathrm{~N}=22$.

Prices are more flexible, and output deviations from trend less persistent, in high inflation economies, although only the post- 73 results are significant. The insignificance of the pre-73 results is unsurprising because there is little variation in inflation in the pre-73 sample of economies.

Table 6 reports the correlation between the autocorrelations of real output and average inflation for various subsamples of the 1949-1994 sample. As with the model based measure $\pi$, the results indicate significantly less persistence in the deviations of real output from trend in high inflation economies. These results again require consideration of the post-73 sample, when there exists some variation in the inflation experiences of the economies.

\section{E. Robustness II}

Previous research has concluded that inflation crises (periods consisting of a rapid acceleration of inflation) result in below average output growth, and that output growth quickly rebounds following the elimination of the crisis (Bruno and Easterly (1995)). These previous findings may raise suspicion that the results in the previous sections rely on the inclusion of crises which are in some sense fundamentally different (and less persistent) than normal business cycle fluctuations.

There are two ways to address this concern. First, as a theoretical matter, the lack of persistence in the output contraction following an inflation crisis is exactly what is predicted by endogenous price stickiness models, because the acceleration of inflation lowers nominal 
rigidities, and hence lowers the persistence of the effects of nominal aggregate demand.

Therefore, the rapid resumption of growth easily fits into the explanation for business cycle persistence offered herein.

Secondly, consideration of different samples from the BMR sample emphasized above reveals that the finding of less business cycle persistence in high inflation countries does not rely on the inclusion of crisis countries. In particular, Lucas (1973) and Alberro (1981) both estimate (14b) for different samples of countries over the pre-1970 period. Consideration of the price flexibility-persistence parameter $\pi$ estimated in these studies avoids the reliance on inflation crises because inflation crises were rare before 1970. Specifically, Bruno and Easterly (1995) identify 26 countries experiencing inflation crises, and only 3 of the 33 crises occurred before 1970 .

The Lucas sample consists of 17 countries over the period 1952-1967 (and no crisis countries), and the Alberro sample consists of 49 countries over the period 1953-1969 (and includes the three crisis countries identified by Bruno and Easterly for the pre-1970 period: Brazil, Indonesia, and Uruguay). ${ }^{9}$ Trend inflation $(\Delta \mathrm{P})$ refers to the average log change of the price level over the period. Lucas and Alberro each remove the trend in real output with a linear trend before estimating (14b), and provide the coefficients on $\mathrm{y}_{\mathrm{t}-1}$ and $\Delta \mathrm{m}_{\mathrm{t}}$ in their versions of (14b). $\pi$ is recovered from these coefficients. The regressions of $\pi$ against $\Delta \mathrm{P}$ yield (heteroskedasticity consistent t-statistics in parentheses)

Lucas: $\pi=0.220+4.133 \Delta \mathrm{P}$

Adj. $\mathrm{R}^{2}=0.34 \quad \mathrm{~N}=17$

Alberro: $\quad \pi=0.353+1.192 \Delta \mathrm{P}$ Lucas.

\footnotetext{
${ }^{9}$ I delete Paraguay from the Lucas sample as Alberro reports large revisions to the Paraguay data used by
} 
In both samples, the results show that countries with higher average inflation rates have more flexible prices (and hence through (14) less persistent deviations of real output from trend). These results remain if the three crisis economies identified by Bruno and Easterly (1995) for the pre-1970 period are deleted from the Alberro sample:

$$
\begin{aligned}
& \pi=0.335+1.530 \Delta \mathrm{P} \\
& \text { (8.05) (2.83) Adj. } \mathrm{R}^{2}=0.10 \quad \mathrm{~N}=46 .
\end{aligned}
$$

In sum, consideration of the Lucas (1973) and Alberro (1981) samples indicates that my finding of less persistence in output fluctuations is not solely a crisis phenomenon, as well as revealing that the predicted effect of inflation on price rigidity, and hence output persistence, can be found in the literature as far back as Lucas (1973); previous research on the cross-country implications of endogenous price stickiness simply didn't look for any relationship between persistence and average inflation.

\section{F. Robustness III}

The final robustness check concerns the most plausible alternative explanation for the finding of less persistence in real output fluctuations in high inflation economies: measurement error. According to this explanation, high inflation makes measurement of real output more difficult, and the higher level of measurement error leads to less autocorrelation in measured real output in high inflation economies. To address this concern, I assume that the measurement error is of the classical type, i.e. uncorrelated over time. This assumption implies that twice lagged values of output are valid instruments for lagged output in (14b). Estimating (14b) for the 43 countries in BMR's sample by instrumental variables yields the estimates of $\pi$ reported in table 7 . Table 8 then reports the correlation of these $\pi$ 's with average inflation in the economy. For the 
full 43 country and non-OECD samples, high inflation countries have larger $\pi$ 's (more flexible prices) and less output persistence (significant at the $1 \%$ level). Note also that the instrumented results for Argentina and Bolivia are large outliers; deleting these countries from the non-OECD sample still results in high inflation economies having less business cycle persistence (and more flexible prices $\pi$; significant at the $5 \%$ level). The OECD sample demonstrates a positive correlation between $\pi$ and average inflation, as expected, but the result is not significant. This insignificance is again unsurprising given the lack of variability of inflation experiences within the OECD sample. In sum, these results again support the conclusion that high inflation economies have less persistent deviations of real output from trend because of price flexibility, and provide no support for the measurement error explanation.

Another implication of measurement error is that high inflation economies should have more variability in measured real output, conditional on the variability of nominal aggregate demand, whereas (14) indicates that the variability of real output should be lower in high inflation economies, conditional on the variability of nominal aggregate demand. Regressing the standard deviation of HP-filtered real output against quadratic terms of inflation $(\Delta \mathrm{P})$ and the standard deviation of nominal output growth $\left(\sigma_{\mathrm{m}}\right)$ (as in BMR) for the BMR and pre-73/post-73 samples yields (t-statistics in parentheses)

$$
\begin{aligned}
& \mathrm{BMR}^{10}: \quad \sigma_{\mathrm{y}}=0.0202-0.3254 \Delta \mathrm{P}+0.6294 \Delta \mathrm{P}^{2}+0.6581 \sigma_{\mathrm{m}}-1.572 \sigma_{\mathrm{m}}^{2} \\
& \begin{array}{llll}
(4.59) \quad(3.22) \quad(3.20) \quad(5.22) \quad(4.35)
\end{array}
\end{aligned}
$$

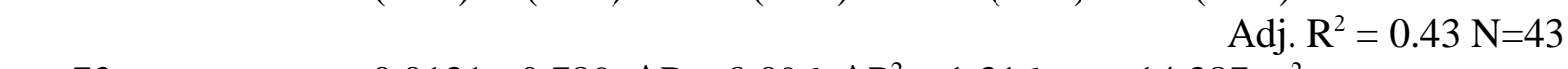

$$
\begin{aligned}
& \text { pre-73: } \quad \sigma_{\mathrm{y}}=0.0131-0.789 \Delta \mathrm{P}+8.096 \Delta \mathrm{P}^{2}+1.316 \sigma_{\mathrm{m}}-14.287 \sigma_{\mathrm{m}}{ }^{2} \\
& \begin{array}{llll}
(1.21) \quad(3.64) \quad(5.50) \quad(2.48) \quad(2.14)
\end{array} \\
& \text { Adj. } \mathrm{R}^{2}=0.68 \mathrm{~N}=16 \\
& \text { post-73: } \quad \sigma_{\mathrm{y}}=-0.0221-0.643 \Delta \mathrm{P}-3.355 \Delta \mathrm{P}^{2}+0.524 \sigma_{\mathrm{m}}+1.661 \sigma_{\mathrm{m}}{ }^{2}
\end{aligned}
$$

\footnotetext{
${ }^{10}$ As reported in BMR.
} 
In the BMR sample, higher inflation clearly lowers real output variability for most values of inflation, including the sample mean $(\Delta \mathrm{P}=0.10)$. In the 16 economy pre-73 sample (in which inflation shows little variation across countries), inflation increases real output variability at the sample mean of 0.05 , while in the post-73 22 economy sample, inflation decreases real output variability at the sample mean of 0.10 . The results are mixed, but at least suggest that higher inflation lowers price stickiness and real output variability. Note that these results suggest that greater measurement error in high inflation economies does not drive the results on persistence or the results of BMR, Lucas, and others on the impact of nominal shocks on real output; if measurement error is the primary explanation for the impact and persistence results discussed herein, high inflation should result in a systematically higher standard deviation of real output in high inflation countries. In fact, I find the opposite in the BMR and post-73 samples.

\section{Conclusion}

To summarize the results, the samples of Lucas (1973) and Alberro (1981) both indicate significantly less persistence in high inflation economies according to (14b) in the pre-1973 time period. The more recent sample excluding Latin America and Africa, as well as the sample of BMR including Latin America and Africa, also indicate less persistence in real output fluctuations in high inflation economies according to both model based measures from (14b) and (14c) (which controls for differences across countries in the persistence of nominal aggregate demand fluctuations), and simple autocorrelations. The systematic relationship between average inflation and the persistence of real output is difficult to reconcile with alternative propagation mechanisms such as real shock persistence and capital accumulation. These results go beyond the standard 
criticism of equilibrium business cycle models regarding the lack of persistence in output generated by these models (Cogley and Nason (1995), Rotemberg and Woodford (1994)) by demonstrating that cross-country differences in persistence are systematically related to inflation as in endogenous sticky price models.

These results revealing the relationship between high inflation and low output persistence about trend mesh nicely with the previous work of BMR, Lucas, and many others indicating smaller real output effects of nominal shocks in high inflation countries. (14) indicates that low impact and persistence of the real effects of nominal shocks when inflation is high follows directly from lower price stickiness in high inflation environments.

\section{I therefore conclude that persistent movements of output around trend disappear with}

high inflation as the persistence generating mechanism (sticky prices) disappears. Unless one is willing to assume that the persistence of real shocks and the importance of capital accumulation, capital and labor adjustment costs, etc., systematically differ across countries with different average inflation rates, the standard equilibrium business cycle persistence generating mechanisms must play a secondary role to price stickiness in explaining the persistence of the deviations of output from trend. 


\section{References}

Alberro, J. (1981) The Lucas Hypothesis on the Phillips Curve: Further International Evidence. Journal of Monetary Economics 7:239-250.

Andersen, T.M. (1994) Price Rigidity: Causes and Macroeconomic Consequences. Oxford University Press.

Ball, L., and Mankiw, N.G. (1994) A Sticky Price Manifesto. Carnegie Rochester Conference Series on Public Policy 41:127-151.

Ball, L., Mankiw, N.G., and Romer D. (1988) The New Keynesian Economics and the Output Inflation Tradeoff. Brookings Papers on Economic Activity 1:1-65.

Bruno, M., and Easterly, W. (1995) Inflation Crises and Long Run Growth. Mimeo (July).

Caballero, R.J. (1989) Time Dependent Rules, Aggregate Stickiness, and Information Externalities. Columbia University Department of Economics Discussion Paper Series No. 428.

Caballero, R.J., and Engel, E.M.R.A. (1992) Price Rigidities, Asymmetries, and Output Fluctuations. NBER Working Paper \# 4091.

Caballero, R.J., and Engel, E.M.R.A. (1993) Microeconomic Rigidities and Aggregate Price Dynamics. European Economic Review 37:697-711.

Calvo, G.A. (1983) Staggered Prices in a Utility Maximizing Framework. Journal of Monetary Economics 12:383-398.

Cogley, T., and Nason, J.M. (1995) Output Dynamics in Real Business Cycle Models. American Economic Review 85:492-511.

Cooley, T.F. and Hansen, G.D. (1995) Money and the Business Cycle. In Cooley, T.F., ed. Frontiers of Business Cycle Research. Princeton University Press. 175-216.

Cuthbertson, K., Hall, S.G., and Taylor, M.P. (1992) Applied Econometric Techniques. University of Michigan Press.

DeFina, R.H. (1991) International Evidence on a New-Keynesian Theory of the Output-Inflation Tradeoff. Journal of Money, Credit, and Banking 23:410-422.

Hume, D. (1752) Of Money. As reproduced in Rotwein, E. (1955) David Hume: Writings on Economics. University of Wisconsin Press. 33-46. 
Kiley, M.T. (1995) Central Bank Independence and the Cost of Disinflation: A Suggested Interpretation. mimeo.

Lucas, R.E. Jr. (1972) Expectations and the Neutrality of Money. Journal of Economic Theory 4:103-24.

Lucas, R.E. Jr. (1973) Some International Evidence on Output Inflation Tradeoffs. American Economic Review 63:326-34.

Lucas, R.E. Jr. (1977) Understanding Business Cycles. In Brunner, K. and Meltzer, A., eds. Stabilization of the Domestic and International Economy. North Holland. 7-29.

Lucas, R.E. Jr. (1987) Models of Business Cycles. Basil Blackwell, Inc.

Romer, D. (1990) Staggered Price Setting with Endogenous Frequency of Adjustment. Economics Letters 32:205-210.

Rotemberg, J.J. (1987) The New Keynesian Microfoundations. NBER Macroeconomics Annual 1987. 69-104.

Rotemberg, J.J. (1994) Prices, Output, and Hours: An Empirical Analysis Based on a Sticky Price Model. NBER Working Paper \#4948.

Rotemberg, J.J., and Woodford, M. (1994) Is the Business Cycle a Necessary Consequence of Stochastic Growth. NBER Working Paper \# 4650.

Taylor, J.B. (1980) Aggregate Dynamics and Staggered Contracts. Journal of Political Economy. 88:1-23.

Taylor, J.B. (1993) Macroeconomic Policy in a World Economy. W.W. Norton and Company.

Walsh, C.E. (1994) Central Bank Independence and the Short-Run Output-Inflation Tradeoff in the E.C. University of California at Berkeley Center for German and European Studies Working Paper \#1.35. 
Figure 1:

$\pi$ when $\mathbf{a}=0$

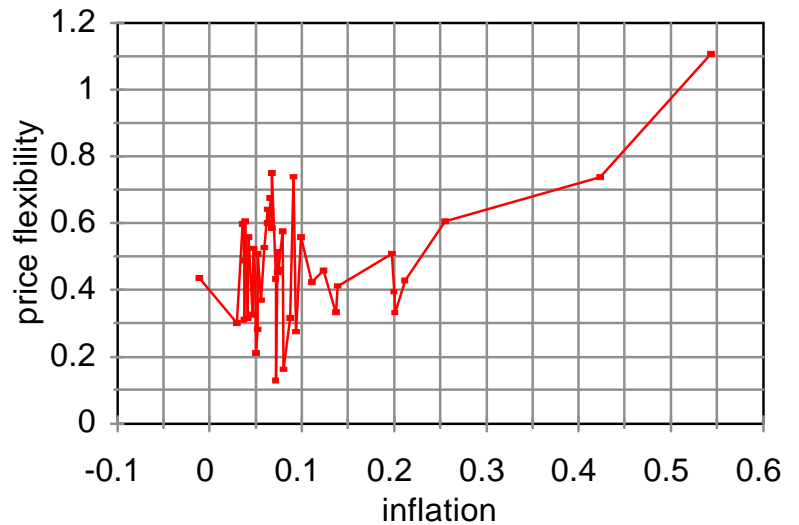

Figure 2:

$\pi$ when $\mathbf{a} \neq 0$

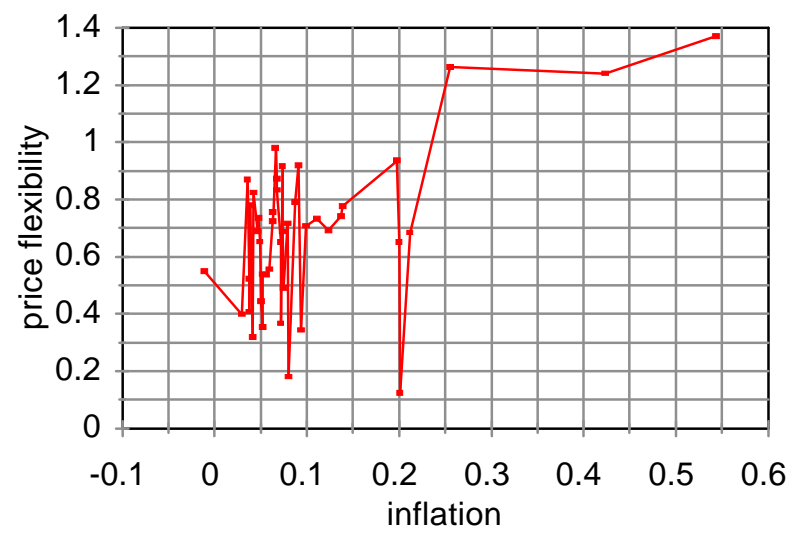


Table 1: Real Output Autocorrelations

\begin{tabular}{|c|c|c|c|c|c|c|c|}
\hline \multirow[t]{2}{*}{ country } & \multicolumn{3}{|c|}{ HP filter } & \multirow{2}{*}{$\begin{array}{l}\text { Linear } \\
\mathrm{y}(-1)\end{array}$} & \multirow[t]{2}{*}{ Trend } & \multicolumn{2}{|r|}{ inflation rate } \\
\hline & $y(-1)$ & $\mathrm{y}(-2)$ & & & & $y(-2)$ & \\
\hline Argentina & & -0.40 & -0.48 & & 0.35 & 0.10 & 0.54 \\
\hline Australia & & 0.37 & -0.10 & & 0.89 & 0.76 & 0.07 \\
\hline Austria & & 0.65 & 0.20 & & 0.93 & 0.81 & 0.05 \\
\hline Belgium & & 0.55 & 0.25 & & 0.93 & 0.81 & 0.04 \\
\hline Bolivia & & 0.74 & 0.37 & & 0.92 & 0.68 & 0.20 \\
\hline Brazil & & 0.47 & -0.06 & & 0.85 & 0.54 & 0.42 \\
\hline Canada & & 0.42 & 0.00 & & 0.83 & 0.61 & 0.05 \\
\hline Colombia & & 0.66 & 0.22 & & 0.89 & 0.67 & 0.14 \\
\hline Costa Rica & & 0.62 & 0.10 & & 0.92 & 0.74 & 0.12 \\
\hline Denmark & & 0.33 & -0.07 & & 0.93 & 0.84 & 0.06 \\
\hline Dominican Republic & & 0.46 & 0.09 & & 0.79 & 0.56 & -0.01 \\
\hline Ecuador & & 0.68 & 0.24 & & 0.89 & 0.68 & 0.09 \\
\hline El Salvador & & 0.75 & 0.29 & & 0.95 & 0.83 & 0.05 \\
\hline Finland & & 0.53 & -0.15 & & 0.82 & 0.53 & 0.07 \\
\hline France & & 0.54 & 0.13 & & 0.96 & 0.88 & 0.07 \\
\hline Germany & & 0.36 & -0.26 & & 0.96 & 0.86 & 0.04 \\
\hline Greece & & 0.31 & 0.15 & & 0.93 & 0.85 & 0.09 \\
\hline Guatemala & & 0.58 & -0.04 & & 0.80 & 0.41 & 0.04 \\
\hline Iceland & & 0.50 & 0.01 & & 0.73 & 0.34 & 0.20 \\
\hline Iran & & 0.73 & 0.26 & & 0.92 & 0.74 & 0.09 \\
\hline Ireland & & 0.59 & 0.04 & & 0.92 & 0.79 & 0.07 \\
\hline Israel & & 0.67 & 0.25 & & 0.93 & 0.76 & 0.21 \\
\hline Italy & & 0.46 & -0.07 & & 0.95 & 0.85 & 0.08 \\
\hline Jamaica & & 0.65 & 0.34 & & 0.92 & 0.78 & 0.11 \\
\hline Japan & & 0.73 & 0.40 & & 0.97 & 0.89 & 0.05 \\
\hline Mexico & & 0.51 & -0.11 & & 0.81 & 0.41 & 0.14 \\
\hline Netherlands & & 0.60 & 0.13 & & 0.93 & 0.79 & 0.05 \\
\hline Nicaragua & & 0.44 & -0.07 & & 0.79 & 0.50 & 0.08 \\
\hline Norway & & 0.63 & 0.14 & & 0.77 & 0.42 & 0.06 \\
\hline Panama & & 0.57 & 0.23 & & 0.87 & 0.69 & 0.03 \\
\hline Peru & & 0.41 & -0.16 & & 0.84 & 0.54 & 0.26 \\
\hline Phillipines & & 0.77 & 0.36 & & 0.90 & 0.60 & 0.07 \\
\hline Portugal & & 0.46 & -0.01 & & 0.80 & 0.56 & 0.07 \\
\hline Singapore & & 0.41 & 0.13 & & 0.64 & 0.38 & 0.04 \\
\hline South Africa & & 0.49 & -0.01 & & 0.94 & 0.84 & 0.07 \\
\hline Spain & & 0.67 & 0.16 & & 0.94 & 0.81 & 0.10 \\
\hline Sweden & & 0.51 & -0.11 & & 0.95 & 0.86 & 0.06 \\
\hline Switzerland & & 0.54 & 0.02 & & 0.95 & 0.85 & 0.04 \\
\hline Tunisia & & 0.56 & 0.18 & & 0.72 & 0.38 & 0.06 \\
\hline United Kingdom & & 0.35 & -0.24 & & 0.87 & 0.72 & 0.07 \\
\hline United States & & 0.54 & 0.00 & & 0.78 & 0.47 & 0.04 \\
\hline Venezuela & & 0.72 & 0.31 & & 0.94 & 0.77 & 0.05 \\
\hline Zaire & & 0.70 & 0.40 & & 0.94 & 0.82 & 0.20 \\
\hline
\end{tabular}


Table 2

Relationship Between Real Output Autocorrelations and Inflation in BMR Sample

\begin{tabular}{|lcccc|}
\hline & \multicolumn{2}{c}{ HP detrended } & \multicolumn{2}{c|}{ Linearly detrended } \\
& $\rho_{1}$ & $\rho_{2}$ & $\rho_{1}$ & $\rho_{2}$ \\
All 43 & $-0.48^{* * *}$ & $-0.31^{* *}$ & $-0.49 * * *$ & $-0.42 * * *$ \\
Countries & & & & \\
$\begin{array}{l}\text { Non-OECD } \\
(22 \text { obs. })\end{array}$ & $-0.63 * * *$ & $-0.54 * * *$ & $-0.47 * *$ & $-0.39 *$ \\
$\begin{array}{l}\text { OECD only } \\
(21 \text { obs. })\end{array}$ & -0.08 & -0.05 & $-0.43^{* *}$ & $-0.43^{* *}$ \\
\hline
\end{tabular}

*** significant at $1 \%$ level

** significant at $5 \%$ level

* significant at $10 \%$ level 
Table 3: Price Flexibility when $\mathbf{a}=0$

\begin{tabular}{|c|c|c|}
\hline Country & $\pi$ & t-statistic \\
\hline Argentina & 1.108 & 3.69 \\
\hline Austria & 0.750 & 5.40 \\
\hline Australia & 0.508 & 3.74 \\
\hline Belgium & 0.557 & 4.57 \\
\hline Bolivia & 0.331 & 1.83 \\
\hline Brazil & 0.738 & 3.13 \\
\hline Canada & 0.525 & 4.23 \\
\hline Colombia & 0.333 & 2.33 \\
\hline Costa Rica & 0.459 & 2.92 \\
\hline Denmark & 0.642 & 4.86 \\
\hline Dominican Republic & 0.436 & 3.35 \\
\hline Ecuador & 0.316 & 2.39 \\
\hline El Salvador & 0.211 & 2.20 \\
\hline Finland & 0.461 & 3.55 \\
\hline France & 0.585 & 3.80 \\
\hline Germany & 0.488 & 3.90 \\
\hline Greece & 0.739 & 5.60 \\
\hline Guatemala & 0.310 & 2.01 \\
\hline Iceland & 0.509 & 3.51 \\
\hline Iran & 0.274 & 2.37 \\
\hline Ireland & 0.452 & 3.28 \\
\hline Israel & 0.428 & 2.87 \\
\hline Italy & 0.575 & 4.11 \\
\hline Jamaica & 0.423 & 2.61 \\
\hline Japan & 0.326 & 2.88 \\
\hline Mexico & 0.411 & 2.72 \\
\hline Netherlands & 0.438 & 3.32 \\
\hline Nicaragua & 0.162 & 0.71 \\
\hline Norway & 0.369 & 2.71 \\
\hline Panama & 0.302 & 2.93 \\
\hline Peru & 0.606 & 3.05 \\
\hline Phillipines & 0.129 & 1.08 \\
\hline Portugal & 0.514 & 3.08 \\
\hline Singapore & 0.598 & 4.04 \\
\hline South Africa & 0.434 & 2.99 \\
\hline Spain & 0.559 & 5.65 \\
\hline Sweden & 0.601 & 4.14 \\
\hline Switzerland & 0.605 & 6.88 \\
\hline Tunisia & 0.527 & 3.01 \\
\hline United Kingdom & 0.675 & 4.07 \\
\hline United States & 0.314 & 3.24 \\
\hline Venezuela & 0.282 & 2.29 \\
\hline Zaire & 0.394 & 2.88 \\
\hline
\end{tabular}


Table 4: Price Flexibility when $a \neq 0$

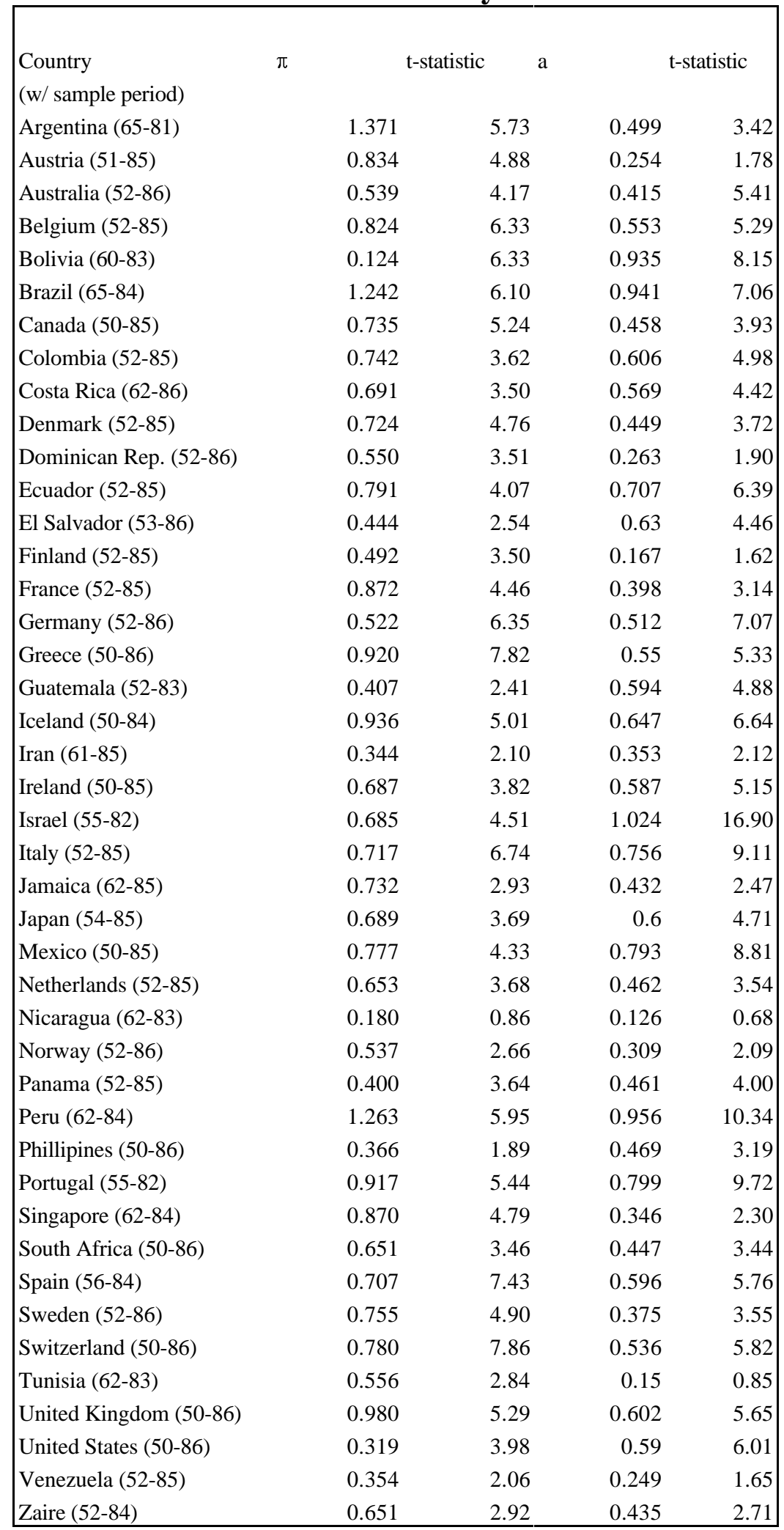


Table 5: 1949-1994 Sample

\begin{tabular}{|c|c|c|c|c|}
\hline \multirow[t]{2}{*}{ country } & \multirow[b]{2}{*}{$\pi$ from $(14 c)$} & \multicolumn{2}{|c|}{ Autocorrelation (HP) } & \multirow[t]{2}{*}{ inflation rate } \\
\hline & & $\mathrm{y}(-1)$ & $\mathrm{y}(-2)$ & \\
\hline Australia (51-73) & 0.811 & 0.28 & -0.327 & 0.051 \\
\hline Australia (76-94) & 0.532 & 0.471 & -0.12 & 0.067 \\
\hline Austria (76-94) & 0.531 & 0.561 & 0.175 & 0.041 \\
\hline Belgium (55-73) & 0.545 & 0.658 & 0.111 & 0.033 \\
\hline Belgium (76-94) & 0.584 & 0.535 & 0.32 & 0.043 \\
\hline Canada (51-73) & 0.562 & 0.35 & -0.123 & 0.033 \\
\hline Canada (76-94) & 0.469 & 0.634 & 0.157 & 0.049 \\
\hline Denmark (52-73) & 0.797 & 0.313 & -0.189 & 0.051 \\
\hline Denmark (76-94) & 0.327 & 0.529 & 0.109 & 0.055 \\
\hline France (52-73) & 0.827 & 0.50 & 0.174 & 0.050 \\
\hline France (76-94) & 0.512 & 0.668 & 0.162 & 0.063 \\
\hline Greece (51-73) & 0.742 & 0.309 & 0.287 & 0.050 \\
\hline Greece (76-93) & 0.562 & 0.491 & 0.076 & 0.157 \\
\hline Iceland (52-73) & 0.633 & 0.409 & -0.05 & 0.117 \\
\hline Iceland (76-94) & 0.826 & 0.578 & -0.121 & 0.252 \\
\hline Iran (76-93) & 0.095 & 0.653 & 0.124 & 0.178 \\
\hline Ireland (51-73) & 0.58 & 0.607 & 0.032 & 0.054 \\
\hline Ireland (76-93) & 0.792 & 0.623 & 0.15 & 0.077 \\
\hline Israel (76-94) & 0.955 & 0.211 & -0.504 & 0.500 \\
\hline Italy (76-92) & 0.668 & 0.651 & 0.02 & 0.113 \\
\hline Japan (57-73) & 0.077 & 0.764 & 0.462 & 0.057 \\
\hline Japan (76-93) & 0.378 & 0.604 & 0.64 & 0.026 \\
\hline Netherlands (58-73) & 0.604 & 0.549 & 0.074 & 0.053 \\
\hline Netherlands (76-94) & 0.506 & 0.765 & 0.407 & 0.032 \\
\hline Norway (51-73) & 0.706 & 0.418 & 0.028 & 0.047 \\
\hline Norway (76-94) & 0.585 & 0.609 & -0.004 & 0.055 \\
\hline Portugal (76-94) & 0.569 & 0.722 & 0.141 & 0.167 \\
\hline Singapore (76-92) & 0.224 & 0.613 & -0.044 & 0.034 \\
\hline Spain (56-94) & 0.705 & 0.662 & -0.263 & 0.073 \\
\hline Spain (76-94) & 0.427 & 0.844 & 0.523 & 0.103 \\
\hline Sweden (52-73) & 0.841 & 0.427 & -0.093 & 0.042 \\
\hline Sweden (76-94) & 0.575 & 0.703 & 0.215 & 0.073 \\
\hline Switzerland (51-73) & 0.637 & 0.628 & 0.033 & 0.039 \\
\hline Switzerland (76-94) & 0.664 & 0.762 & 0.042 & 0.033 \\
\hline United Kingdom (51-73) & 0.838 & 0.252 & -0.451 & 0.046 \\
\hline United Kingdom (76-94) & 0.633 & 0.738 & 0.21 & 0.077 \\
\hline United States (51-73) & 0.183 & 0.584 & 0.129 & 0.031 \\
\hline United States (76-94) & 0.517 & 0.564 & -0.052 & 0.050 \\
\hline
\end{tabular}


Table 6

Relationship Between Real Output Autocorrelations and Inflation 1949-1994 Sample (with 1973 split and excluding Latin America and Africa)

\begin{tabular}{|lcc|}
\hline & \multicolumn{2}{c|}{ HP detrended } \\
& $\rho_{1}$ & $\rho_{2}$ \\
All 38 & -0.23 & $-0.37 * *$ \\
Observations & & \\
$\begin{array}{l}\text { Pre-1973 } \\
(16 \text { obs. })\end{array}$ & -0.02 & -0.09 \\
$\begin{array}{l}\text { Post-1973 } \\
(22 \text { obs. })\end{array}$ & $-0.59 * * *$ & $-0.63 * * *$ \\
\hline
\end{tabular}

$* * *$ significant at $1 \%$ level

$* *$ significant at $5 \%$ level 
Table 7: Price Flexibility in (14b) Estimated by Instrumental Variables:

BMR Sample

\begin{tabular}{|c|c|c|}
\hline Country & $\pi$ & istic \\
\hline Argentina & 17.2858 & 0.0985 \\
\hline Austria & 1.41 & 2.83 \\
\hline Australia & 0.88 & 3.02 \\
\hline Belgium & 0.66 & 2.73 \\
\hline Bolivia & 0.02 & 0.06 \\
\hline Brazil & 1.22 & 1.03 \\
\hline Canada & 0.73 & 2.37 \\
\hline Colombia & 0.69 & 2.68 \\
\hline Costa Rica & 0.64 & 2.26 \\
\hline Denmark & 1.43 & 2.33 \\
\hline Dominican Republic & 0.66 & 1.89 \\
\hline Ecuador & 0.62 & 2.89 \\
\hline El Salvador & 0.41 & 3.16 \\
\hline Finland & 1.13 & 3.39 \\
\hline France & 0.83 & 2.62 \\
\hline Germany & 0.99 & 2.35 \\
\hline Greece & 0.73 & 1.03 \\
\hline Guatemala & 0.95 & 2.43 \\
\hline Iceland & 1.02 & 2.79 \\
\hline Iran & 0.57 & 3.14 \\
\hline Ireland & 0.99 & 3.20 \\
\hline Israel & 0.74 & 2.58 \\
\hline Italy & 1.17 & 2.99 \\
\hline Jamaica & 0.57 & 2.15 \\
\hline Japan & 0.46 & 2.83 \\
\hline Mexico & 1.25 & 2.90 \\
\hline Netherlands & 0.75 & 3.03 \\
\hline Nicaragua & 1.15 & 1.66 \\
\hline Norway & 0.76 & 3.06 \\
\hline Panama & 0.33 & 1.55 \\
\hline Peru & 1.26 & 2.08 \\
\hline Phillipines & 0.44 & 2.42 \\
\hline Portugal & 0.94 & 2.37 \\
\hline Singapore & 0.46 & 1.42 \\
\hline South Africa & 0.99 & 2.54 \\
\hline Spain & 0.74 & 5.31 \\
\hline Sweden & 1.19 & 3.61 \\
\hline Switzerland & 0.60 & 3.59 \\
\hline Tunisia & 1.08 & 2.59 \\
\hline United Kingdom & 2.39 & 1.85 \\
\hline United States & 0.71 & 2.87 \\
\hline Venezuela & 0.52 & 2.65 \\
\hline Zaire & 0.55 & 2.47 \\
\hline
\end{tabular}

Table 8 


\section{Relationship Between Price Flexibility $(\pi)$ and Inflation: Instrumental Variable Results in BMR Sample}

\begin{tabular}{|ll|}
\hline \multicolumn{2}{|c|}{ Correlation between $\pi$ and Inflation } \\
All 43 Observations & $0.68 * * *$ \\
Non-OECD (22 obs.) & $0.71 * * *$ \\
$\begin{array}{l}\text { OECD } \\
(21 \text { obs.) }\end{array}$ & 0.14 \\
$\begin{array}{l}\text { Non-OECD } \\
\text { (excluding Argentina } \\
\text { and Bolivia: } 20 \text { obs.) }\end{array}$ & $0.49 * *$ \\
\hline
\end{tabular}

*** significant at $1 \%$ level

** significant at 5\% level 